\title{
Contact guidance enhances the quality of a tissue engineered corneal stroma
}

\author{
E. Vrana, ${ }^{1}$ N. Builles, ${ }^{2}$ M. Hindie, ${ }^{1}$ O. Damour, ${ }^{2}$ A. Aydinli ${ }_{,}^{3}$ V. Hasirci ${ }^{1}$ \\ ${ }^{1}$ BIOMAT, Department of Biological Sciences, Biotechnology Research Unit, Middle East Technical University, \\ Ankara 06531, Turkey \\ ${ }^{2}$ Laboratoire des Substituts Cutanés, Service de Biochimie C, Hôpital Edouard Herriot, \\ Place d'Arsonval, F-69437 Lyon Cedex 03, France \\ ${ }^{3}$ Department of Physics, Bilkent University, Ankara 06800, Turkey
}

Received 17 October 2006; revised 30 November 2006; accepted 23 March 2007

Published online 6 July 2007 in Wiley InterScience (www.interscience.wiley.com). DOI: 10.1002/jbm.a.31442

\begin{abstract}
Corneal stroma is a very complex structure, composed of 200 lamellae of oriented collagen fibers. This highly complex nature of cornea is known to be important for its transparency and mechanical integrity. Thus, an artificial cornea design has to take into account this complex structure. In this study, behavior of human corneal keratocytes on collagen films patterned with parallel channels was investigated. Keratocytes proliferated well on films and reached confluency after 7 days in the incubation medium. Nearly all of the cells responded to the patterns and were aligned in contrast to the cells on unpatterned surfaces. Collagen type I and keratan sulfate secreted by keratocytes on patterned films appeared to be aligned in the direction of the patterns. The films showed an intermediate degradation over the course of a month. On the whole,
\end{abstract}

transparency of the films increased with degradation and decreased by the presence of the cells. The decrease was, however, low and transparency level was maintained on the patterned films while on the unpatterned films a sharp decrease in transparency was followed by an improvement. This was due to the more organized distribution of cells and the oriented secretion of extracellular matrix molecules on patterned collagen films. Thus, these results suggest that application of contact guidance in cornea tissue engineering may facilitate the remodeling process, hence decrease the rehabilitation period. (C) 2007 Wiley Periodicals, Inc. J Biomed Mater Res 84A: 454-463, 2008

Key words: tissue engineering; cornea; micropatterning; collagen; transparency

\section{INTRODUCTION}

Cornea is the outermost layer of the eye. It protects the eye from physical damages and also has a role in focusing of light. ${ }^{1}$ Although cornea has good regenerative capabilities, deep wounds and certain dystrophies may result in irreversible corneal damages. ${ }^{2-4}$ Since cornea is avascular, as a remedy cornea transplantation has been quite successful, but due to the donor shortage problems artificial corneas have become promising alternatives as they are more readily available and dependable.

The thickest part of the cornea is the stroma, which has a thickness of $500 \mu \mathrm{m}$ and is composed of around 200 lamellae of oriented collagen fibrils surrounded with several types of proteoglycans and quiescent cells, the keratocytes, which are responsible of the maintenance of this structure. ${ }^{5,6}$ The main reason

Correspondence to: V. Hasirci; e-mail: vhasirci@metu.edu.tr Contract grant sponsor: EU FP6

(C) 2007 Wiley Periodicals, Inc. behind the transparency of the cornea appears to be the orientation of the collagen fibrils and the resultant "destructive interference" of the incoming light. ${ }^{7}$ The loss of collagen orientation and absence of certain proteoglycans within the corneal stroma leads to a decrease in corneal clarity and is a strong evidence supporting the above statement. ${ }^{8}$ Orthogonal orientation of collagen fibers in successive lamella, amount and distribution of GAG molecules, and hydration of the stroma all contribute to the transparency. Thus, the highly organized structure of the cornea is essential for its function.

Response of cells to topographical features of a surface is known as contact guidance. ${ }^{9}$ Cells respond to the topographical features mainly through their focal adhesion complexes, which results in an effect of the topography on cellular orientation, which in turn triggers several events. ${ }^{10}$ Effects of the presence of topographical and chemical surface cues have been investigated with several cell types, and patterned surfaces have been shown to affect cell orientation, gene expression, and differentiation. ${ }^{11-13}$ These properties have been used to control direction of growth of neu- 
rites and myofibroblasts. ${ }^{14,15}$ Moreover, patterned surfaces are also effective in controlling the orientation of newly secreted ECM components; thus, contact guidance can be used to manipulate the development process of the artificial tissues and the repair of the damaged natural tissues. All these are also applicable to the production of cell carriers for highly oriented tissues such as ligaments, muscle, and, of course, cornea.

There has been many attempts to create artificial corneas. For corneal stroma applications, foams and meshes have been the main scaffold forms used. Collagen foams have been tried with human keratocytes and they were conducive to cell proliferation and had good mechanical properties. ${ }^{16}$ There have been in vivo trials with PGA meshes where they were observed to become transparent after a period of 4 months. ${ }^{17} \mathrm{Col}-$ lagen was also used in gel form to serve as a scaffold for keratocyte growth. ${ }^{18,19}$ However, in all these systems structural changes that convert a scaffold into an artificial cornea must be done by the keratocytes present, without any physical cues that would guide the secretion of newly synthesized ECM molecules. Incorporation of such cues into an artificial cornea scaffold is important in the development of anisotropy, an inherent property of cornea which in return is crucial for both its mechanical strength and transparency. It has been shown that keratocytes strongly respond to the presence of micropatterns; thus utilization of micropatterning in guiding keratocyte behavior should be beneficial. A surface pattern composed of repeating ridges and grooves, a groove depth significantly higher than the dimensions of the keratocytes, and a groove width narrow enough to direct their orientation should be advantageous for confinement and alignment of the cells and provide control over the direction of the ECM secretion. Since the main ECM component of the natural cornea is collagen type I, collagen should be one of the main candidates in the design of a cornea substitute. Contact guidance by micropatterned collagen films has also been tried and was shown to be effective in aligning the cells. ${ }^{20,21}$

In this study, the effect of patterns on films of collagen on human corneal keratocyte behavior was investigated. Degradation of collagen films and its effect on the transparency of the films were studied. Also, the effect of presence of the patterns on ECM secretion and on film transparency was studied.

\section{MATERIALS AND METHODS}

\section{Materials}

Rat tail type I collagen (purity 99\%) was bought from BD Sciences (USA). EDC (N-ethyl- $N^{\prime}$-[3-dimethyl aminopropyl] carbodiimide), N-hydroxy succinimide (NHS), newborn calf serum, trypsin in EDTA, Amphothericin B, monoclonal anti-collagen type I antibody, glutaraldehyde, cacodylic acid (sodium salt), and DAPI were purchased from Sigma-Aldrich Corporation (Germany). Dulbecco's modified Eagle medium (DMEM) low glucose was obtained from PAA (Austria), Alexafluor488 conjugated anti-mouse Ig antibody was from Molecular Probes (USA) and b-FGF (basic fibroblastic growth factor) was from Invitrogen (USA). DMEM high glucose and Ham F-12 medium were supplied by Gibco (USA), Anti-human keratan sulfate antibody was from Chemicon (USA), acetic acid, sodium dihydrogen phosphate, disodium hydrogen phosphate were obtained from Merck (Germany), NucleoCounter reagents were supplied by Chemometec (Denmark), MTS cell proliferation assay solution was from Promega (USA), and Sylgard 184 elastomer solution was bought from Dow Corning (USA). Collagenase A was purchased from Roche (Switzerland).

\section{Template preparation}

The primary silicon templates with predetermined dimensions (groove width: $2 \mu \mathrm{m}$, ridge width: $10 \mu \mathrm{m}$, groove depth: $30 \mu \mathrm{m}$, inclination angle $54.7^{\circ}$ ) were designed at METU and then manufactured at Bilkent University Physics Department by photolithography and chemical etching. The secondary (elastomer) templates with patterns inverse of the primary wafers were also produced by the same lab by pouring Sylgard 184 elastomer onto the primary templates and heat curing $\left(45 \mathrm{~min}, 100^{\circ} \mathrm{C}\right)$. The solidified elastomer was peeled off and had the following dimensions: groove width: $10 \mu \mathrm{m}$; ridge width: $2 \mu \mathrm{m}$; groove depth: $30 \mu \mathrm{m}$; inclination angle $54.7^{\circ}$.

\section{Film preparation}

Micropatterned and unpatterned collagen films were prepared with solvent casting. Collagen solution $(15 \mathrm{mg} /$ $\mathrm{mL}$ in $0.5 \mathrm{M}$ acetic acid) was prepared by mild agitation at $30^{\circ} \mathrm{C}, 200 \mu \mathrm{L}$ of this solution was poured onto the patterned or unpatterned PDMS template (secondary) surface and air dried overnight under the hood. Square shaped (dimensions: $1 \mathrm{~cm} \times 1 \mathrm{~cm}$ ) dry films were removed from the template, their thickness was measured by a standard micrometer, and they were stored in a desiccator at room temperature until use.

Film stabilization

Collagen films were crosslinked by carbodimide based crosslinker system EDC/NHS crosslinking. Scaffolds were immersed into a solution of EDC/NHS (33 and $6 \mathrm{mM}$, respectively) in $\mathrm{NaH}_{2} \mathrm{PO}_{4}$ buffer ( $\mathrm{pH}$ 5.5) for $2 \mathrm{~h}$ at room temperature. The $\mathrm{pH}$ of the system was then brought to neutral by incubating the scaffolds in phosphate buffer (pH 9.1) for $1 \mathrm{~h}$, followed by washing in $2 \mathrm{M}$ and $1 \mathrm{M} \mathrm{NaCl}$ solutions and in distilled water. 
Degradation in situ

To study the degradation profile, scaffolds were incubated under normal culture conditions (in sterile 24-well plates at $37^{\circ} \mathrm{C}$ and under $5 \% \mathrm{CO}_{2}$ ) in sterile PBS ( $\mathrm{pH} 7.4$ ). Degradation was studied at 1, 2, and 4 weeks with SEM, stereomicroscopy, gravimetry, and measurements of the $\mathrm{pH}$ of the medium.

\section{Keratocyte isolation}

Keratocytes were isolated from the cornea of a 28-yearold human male removed in accordance with ethical regulations, using collagenase A $\left(3 \mathrm{mg} / \mathrm{mL}, 3 \mathrm{~h}, 31^{\circ} \mathrm{C}\right)$ and stirring at $200 \mathrm{rpm}$. The digest was purified by filtering through a $70-\mu \mathrm{m}$ cell sieve (BD Falcon). Cells were immediately seeded in monolayer culture at $10,000 / \mathrm{cm}^{2}$ density and cultured at $37^{\circ} \mathrm{C}$ with $5 \% \mathrm{CO}_{2}$. The cells were amplified until passage 4 in a specially designed medium consisting of DMEM/HAM-F12 50/50 DMEM Glutamax (Gibco), HAM's F12 L-Glutamine (Gibco), 10\% new-born calf serum (Hyclone), $5 \mathrm{ng} / \mathrm{mL} \beta$-FGF (Sigma), Penicillin $100 \mathrm{UI} / \mathrm{mL}$ (Sarbach), Gentamicin $20 \mu \mathrm{g} / \mathrm{mL}$ (Dakota), Amphotericin B $1 \mu \mathrm{g} / \mathrm{mL}$ (BMS) to preserve their phenotype. $^{22}$ In all the experiments, keratocytes between passages $4-8$ were used.

\section{Cell proliferation on scaffolds}

To examine the cell proliferation on the films, MTS cell proliferation assay was carried out in triplicates on days 1, 4,7 , and 10. At each time point, the medium was discarded and the well was washed with sterile PBS to remove any remaining medium. MTS solution $(500 \mu \mathrm{L}$, $10 \%)$ was added and scaffolds were incubated $\left(37^{\circ} \mathrm{C}, 5 \%\right.$ $\mathrm{CO}_{2}$ ). After $2 \mathrm{~h}, 100 \mu \mathrm{L}$ of the solution was transferred to a 96-well Elisa plate and absorbance was determined at 490 $\mathrm{nm}$ by a ELISA plate reader (Molecular Devices, USA). To correlate the absorbance with the cell number, a calibration curve was constructed as predetermined cell numbers versus absorbance.

\section{DAPI staining}

Keratocyte seeded films were stained with the nuclear stain DAPI. After fixation in formaldehyde solution $(4 \%$, $15 \mathrm{~min}$ ) the specimens were rinsed with PBS and DAPI solution (diluted 1:1000 in PBS) was applied onto the scaffolds and the whole set was incubated in the dark at $37^{\circ} \mathrm{C}$ for $45 \mathrm{~min}$. Afterwards, specimens were rinsed with PBS and examined with an Olympus IX-70 fluorescence microscope with WU filter (330-385 nm).

\section{SEM examination}

Collagen films seeded with keratocytes were fixed after days 7 and 14 with glutaraldehyde $(2.5 \%$ in cacodylate buffer, $\mathrm{pH} 7.4$ ) for $2 \mathrm{~h}$ and then washed with cacodylate buffer and with distilled water several times and freeze dried. Afterwards samples were gold coated by sputtering and observed with a scanning electron microscope (JSM 6400, JEOL, Japan).

\section{Collagen type I staining}

To study the extracellular matrix (ECM) secretion by the keratocytes indirect immunostaining with anti-collagen type I antibody was performed. Films were seeded with keratocytes and were fixed with $2.5 \%$ formaldehyde for 15 min on days 1 and 7. After washing with PBS, cell membrane was permeabilized with $1 \%$ Triton-X100 solution for $5 \mathrm{~min}$, After washing the samples were incubated at $37^{\circ} \mathrm{C}$ for $1 \mathrm{~h}$ in 1\% PBS-BSA solution. Anti-human collagen type I antibody produced in mice (1:200 dilution in 0.1\% PBSBSA solution) was then added onto the specimens and they were incubated for $1 \mathrm{~h}$ at $37^{\circ} \mathrm{C}$. Samples were washed with $0.1 \%$ PBS-BSA solution and Alexafluor488-labeled Anti-mouse antibody produced in goat (1:100 dilution in $0.1 \%$ BSA-PBS) was added and incubated at $37^{\circ} \mathrm{C}$ for another hour and then washed with $0.1 \%$ PBS-BSA solution. Samples were observed under Olympus IX-70 (Japan) fluorescence microscope with WB filter (450-480 nm). To detect the nonspecific staining of the scaffold collagen type I same procedure was performed on unseeded patterned collagen films.

\section{Keratan sulfate staining}

To determine the presence of keratocyte-specific proteoglycan, keratan sulfate, films seeded with keratocytes were stained for keratan sulfate on days 1 and 7 with indirect immunostaining. Samples were fixed with $2.5 \%$ formaldehyde for 15 min. After washing with PBS ( $\mathrm{pH} \mathrm{7.4),} \mathrm{cell}$ membrane was permeabilized with $1 \%$ Triton-X 100 for $5 \mathrm{~min}$. Samples were washed with PBS and incubated at $37^{\circ} \mathrm{C}$ for $1 \mathrm{~h}$ in $1 \%$ PBS-BSA solution. After washing, antihuman keratan sulfate antibody produced in mice $1: 100$ dilution in $0.1 \%$ BSA-PBS) was added onto the specimens and samples were incubated for $1 \mathrm{~h}$ at $37^{\circ} \mathrm{C}$. Then samples were washed, Alexafluor488-labeled anti-mouse antibody produced in goat (1:100 dilution in $0.1 \%$ BSA-PBS) was added, and incubated at $37^{\circ} \mathrm{C}$ for another hour. Washed samples were observed under Olympus IX-70 (Japan) fluorescence microscope with WB filter (450-480 nm).

\section{Transparency measurement}

Transparency of the scaffolds were studied with a Shimadzu $2100 \mathrm{~S}$ UV-vis spectrophotometer by scanning in the range of $250-700 \mathrm{~nm}$ in quartz cuvettes. Transparency of patterned and unpatterned, keratocyte seeded and unseeded films were determined on days $0,1,4$, and 7 .

\section{Statistical analysis}

Statistical analysis was carried out by Student's $t$-test; $p \leq 0.05$ was considered significant. For the comparison of 

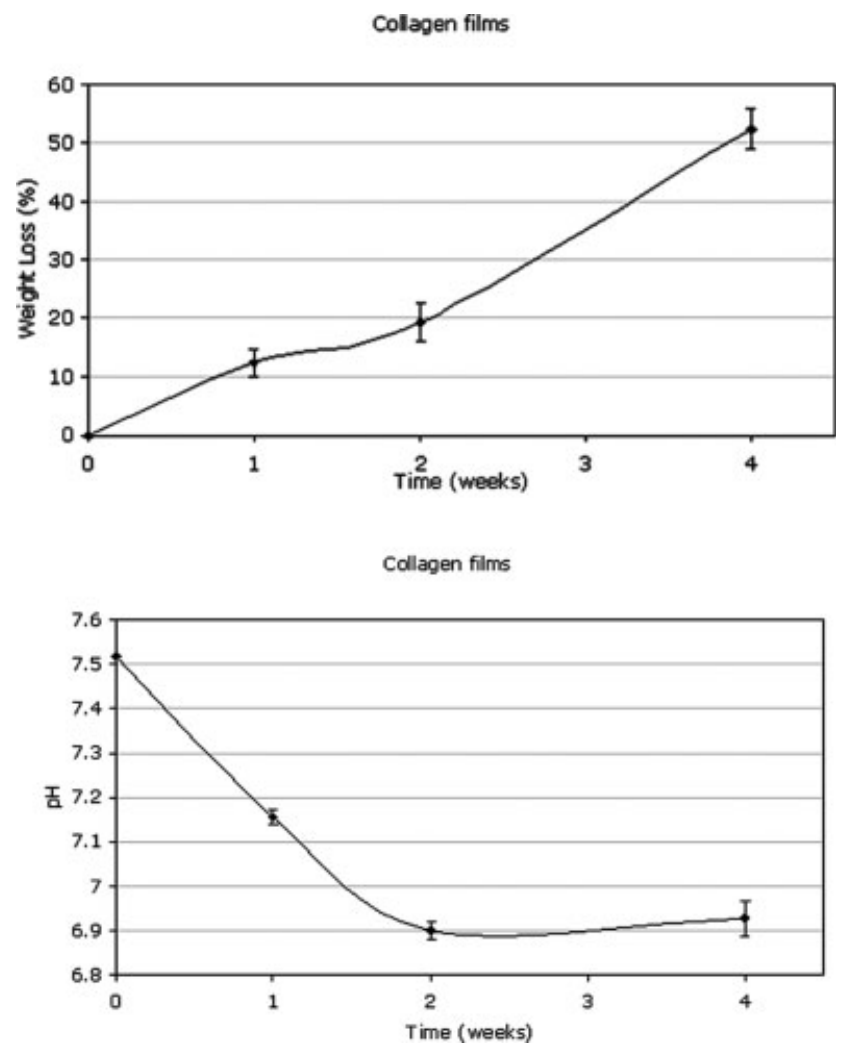

Figure 1. In situ degradation of patterned collagen films in $0.1 \mathrm{M}$ PBS $(\mathrm{pH} 7.4)$ at $37^{\circ} \mathrm{C}$. A: Percentage weight loss of patterned collagen films over 1 month. $\mathrm{B}$ : $\mathrm{pH}$ change of the degradation medium over 1 month.

the transparency data ANOVA-test was performed and significance limit was set as $p \leq 0.05$. For the correlation of cell presence and degradation with the change in transparency, Pearson correlation coefficients were determined.

\section{RESULTS AND DISCUSSION}

\section{Film preparation and degradation}

In this study, effect of patterned collagen films on human corneal keratocyte behavior was investigated. Films had a thickness of $42 \pm 0.3 \mu \mathrm{m}$ and this did not change by crosslinking. Crosslinking did not affect the patterns either.

For integration of a tissue engineered product with the host body the rate of degradation and the effect of degradation on carrier properties are of utmost importance. Scaffold should have an optimal degradation rate because a rapid degradation compromises its structural stability while a slow degradation may delay remodeling and decrease the effectiveness of the scaffold. Rat tail collagen is highly soluble in the aqueous medium which leads to immediate dissolution of an uncrosslinked scaffold. The effect of crosslinking on the film stabilization was assessed in situ for a 1-month period. During this period, films did not lose their shape and integrity, but there was an apparent weight loss during the experiment [Fig. 1(a)]. By the end of the month the weight loss was $52.3 \% \pm 3.4 \%(p=0.028)$. On the other hand, uncrosslinked films immediately lost their shape and completely dissolved in $2 \mathrm{~h}$. There was also a slight decrease in the $\mathrm{pH}$ of the incubation medium which might be due to the hydrolysis of the collagen fibers and exposure of acidic groups [Fig. 1(b)]. Stereomicroscopic observation of the degraded samples did not reveal any extensive deterioration of the patterns. SEM micrographs, however, demonstrated the effect of degradation on surface features [Fig. 2(a,b)].

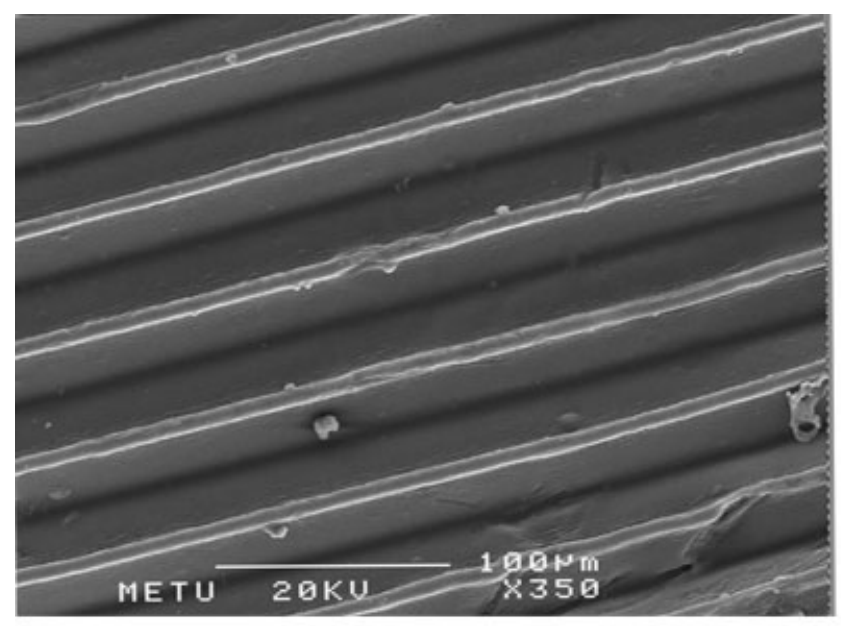

(A)

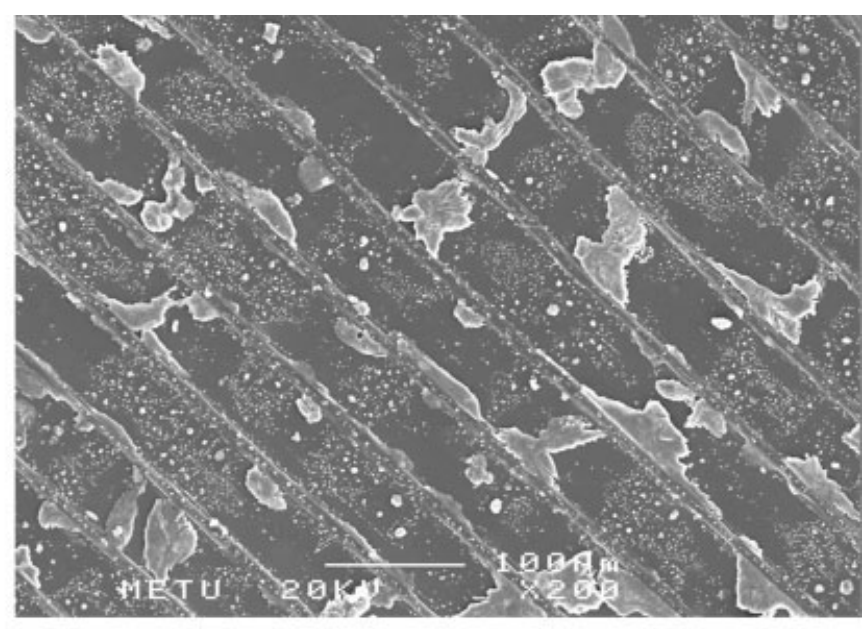

(B)

Figure 2. Effect of degradation on surface patterns of collagen films. SEM micrographs of (A) crosslinked patterned collagen film before degradation and (B) crosslinked patterned collagen film after 1-month incubation in 0.1M PBS (pH 7.4) at $37^{\circ} \mathrm{C}$. 


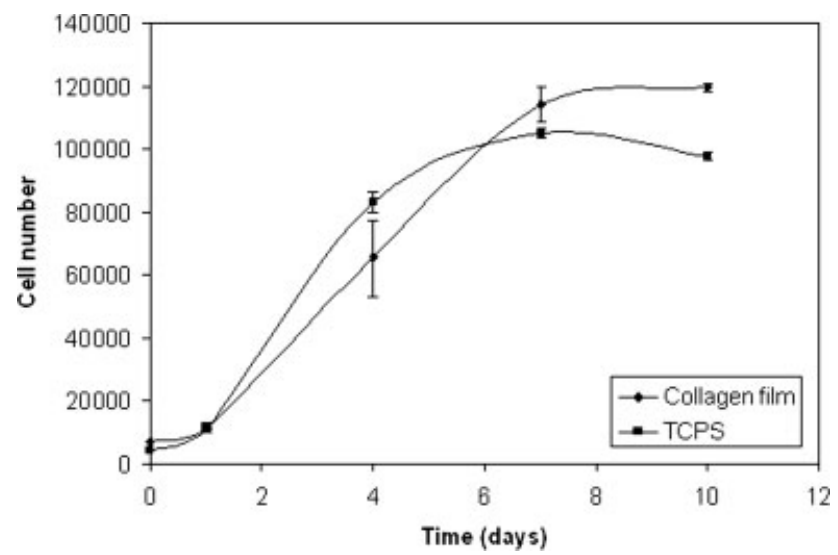

Figure 3. Keratocyte growth curve on tissue culture plate and patterned collagen films for 10 days in an incubator under $5 \% \mathrm{CO}_{2}, 37^{\circ} \mathrm{C}$. Initial cell seeding density: $1 \times 10^{4} /$ scaffold.

\section{Cell proliferation}

MTS assay for cell proliferation showed a steady cell number increase for 7 days and leveling off by day 10. Final cell number on the films was $1.68 \times 10^{5}$ $\pm 8 \times 10^{3}$ on the 10th day; a number less than that of the TCPS control $\left(2.5 \times 10^{5} \pm 2.7 \times 10^{3}\right)$. A TCPS well has a surface area of $2.54 \mathrm{~cm}^{2}$. The presence of the patterns increase the total surface area of a $1-\mathrm{cm}^{2}$ film to $1.47 \mathrm{~cm}^{2}$. As a result the patterned film has a smaller area than the TCPS. When normalized by taking the surface area into account, on day 10 the cell densities (no. of cells $/ \mathrm{cm}^{2}$ ) on control and patterned collagen films were almost the same $\left(9.8 \times 10^{4}\right.$ and $1.2 \times 10^{5}$ ), respectively (Fig. 3). On tissue culture flasks, when confluent, keratocyte density was around 160,000 cells $/ \mathrm{cm}^{2}$, a number higher than that obtained on patterned films. In some literature, effect of presence of patterns on cell growth has been shown to be insignificant ${ }^{11,23}$; Vernon et al. observed similar cell numbers for human dermal fibroblasts and artery smooth muscle cells on collagen films and on TCP. ${ }^{21}$ Highest cell number reached on TCP control was $2.69 \times 10^{5} \pm 4 \times 10^{3}$ on day 7 and then declined on day 10. This might be due to attainment of confluency sometime between days 7 and 10, followed by subsequent cell detachment and apoptosis.
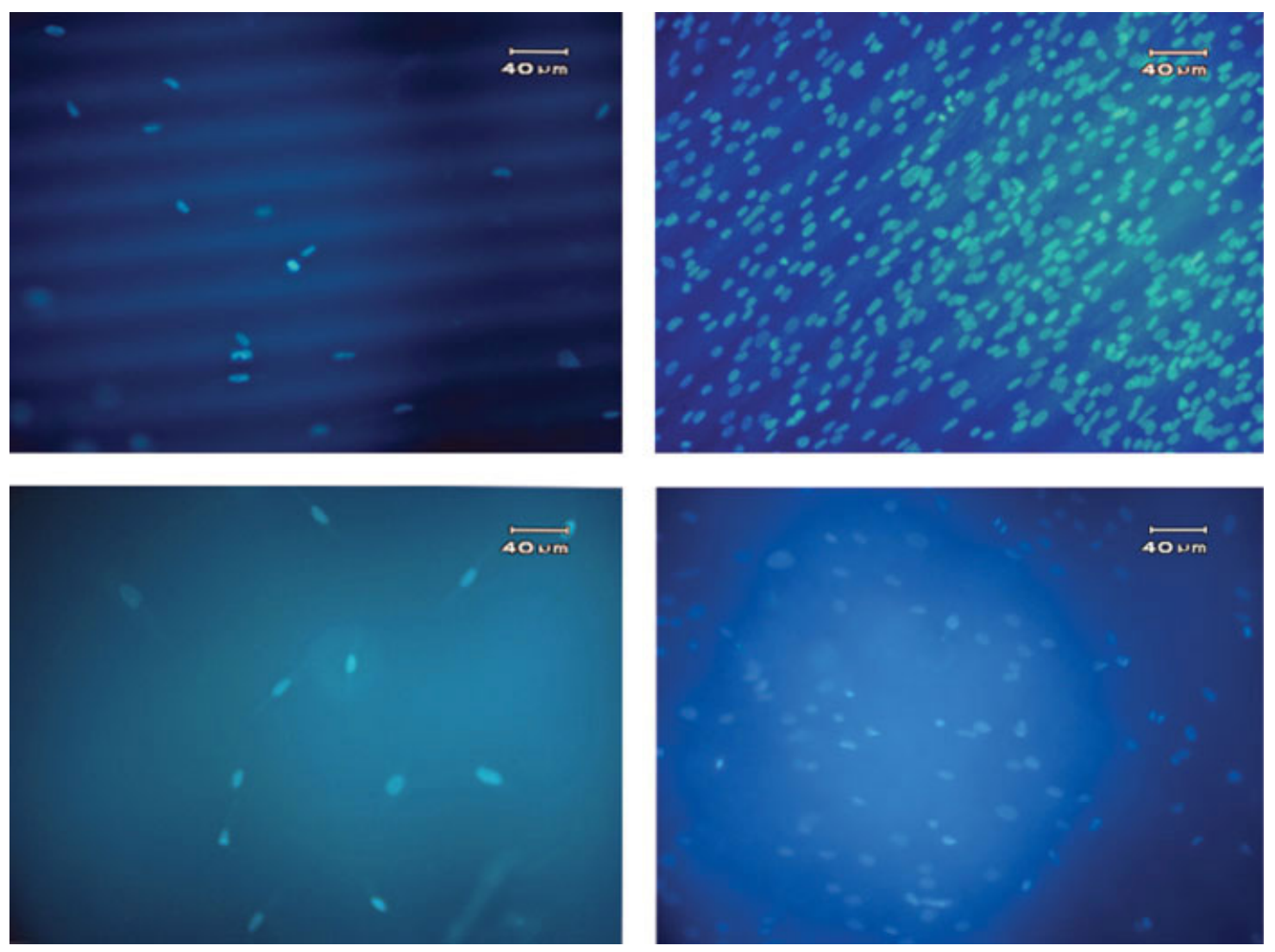

Figure 4. Fluorescent micrographs of DAPI-stained keratocytes on patterned and unpatterned collagen films. Patterned films: (A) day 1, (B) day 7; unpatterned films: (C) day 1, (D) day 7 (top left, top right, bottom left and bottom right, respectively). Oriented cells can be seen on patterned films and surface coverage can be observed both in patterned and unpatterned films on day 7. [Color figure can be viewed in the online issue, which is available at www.interscience.wiley.com.] 


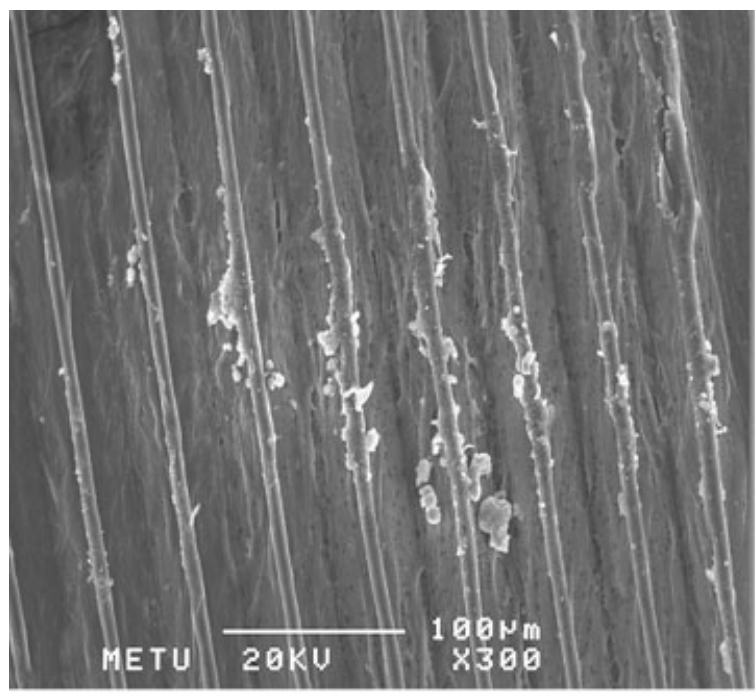

(A)

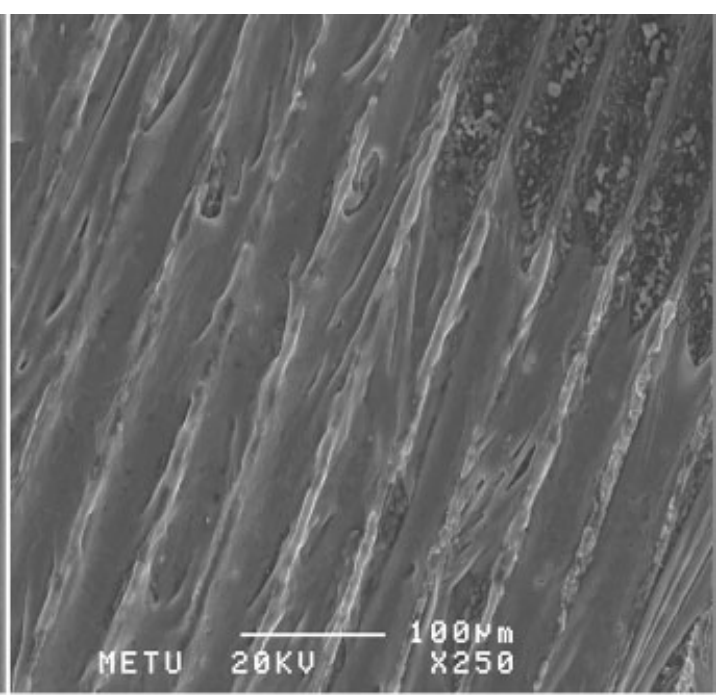

(B)

Figure 5. SEM micrographs of keratocyte seeded patterned collagen films. (A) Day 7; (B) day 14. Aligned, elongated cells can been seen on day 7 .
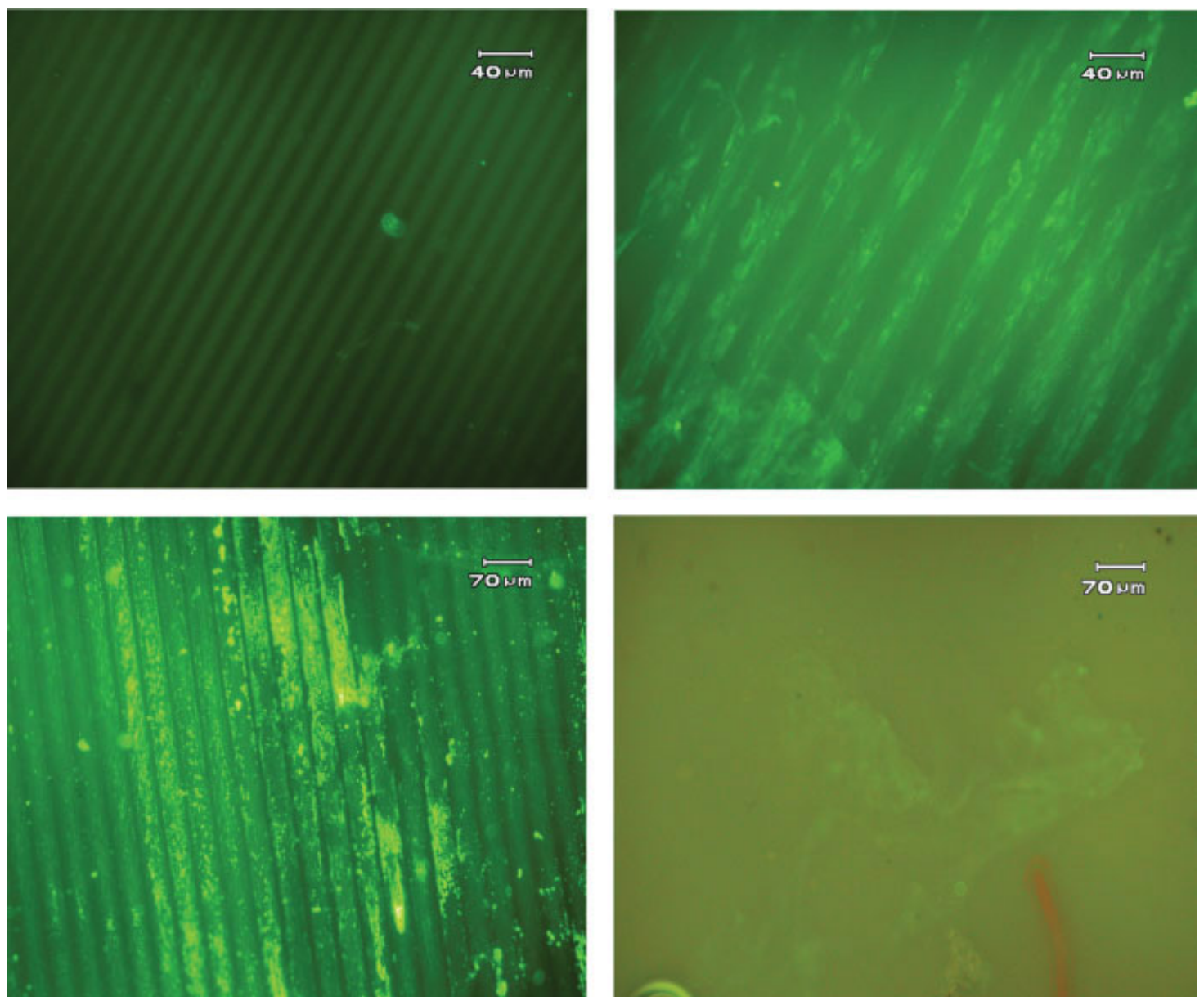

Figure 6. Fluorescent micrographs of collagen type I staining on patterned and unpatterned films seeded with keratocytes. (A) Control (unseeded collagen film); (B) patterned film day 1; (C) patterned film day 7; (D) unpatterned film day 7 (top left, top right, bottom left and bottom right, respectively). [Color figure can be viewed in the online issue, which is available at www.interscience.wiley.com.] 

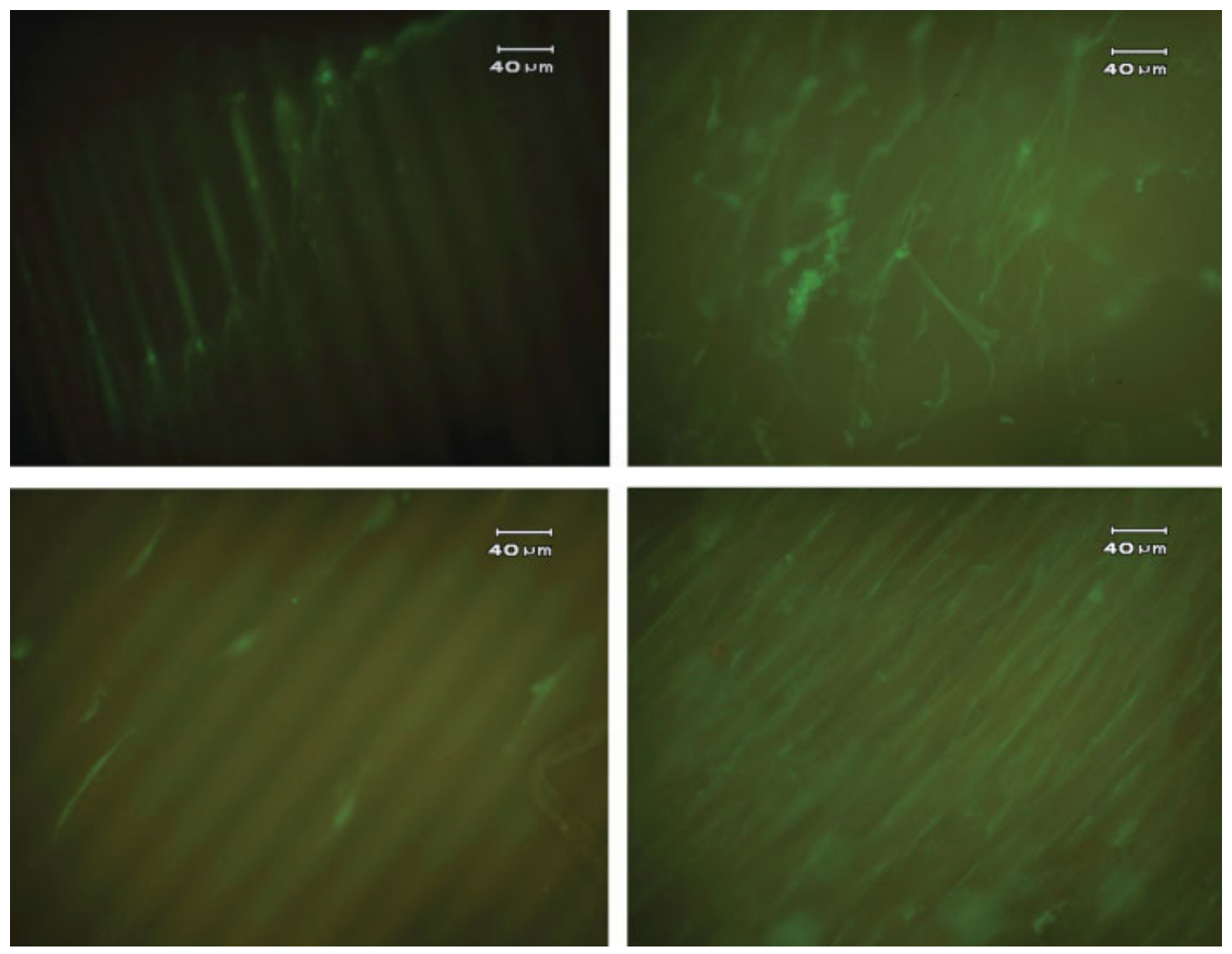

Figure 7. Fluorescent micrographs of keratan sulfate staining on patterned and unpatterned films seeded with keratocytes. (A) Control; (B) unpatterned film day 7; patterned film: (C) day 1, (D) day 7 (top left, top right, bottom left and bottom right, respectively). [Color figure can be viewed in the online issue, which is available at www.interscience.wiley.com.]

\section{Microscopy}

Keratocytes strongly responded to surface patterns and even on day 1 they were aligned in the direction of the grooves. After 7 days, cell proliferation was apparent and the cells were nearly confluent on the patterned film surface [Fig. 4(b)]. Alignment was not lost during this period.

In unpatterned films no anisotropy was observed on day 7; the cells covered the surface evenly and cell morphology resembled that of the keratocytes in tissue culture plates (keratocytes grow in a concentric fashion) [Fig. 4(d)]. Previously it was shown that corneal keratocytes respond to surface patterns in both nanoscale and microscale, in which the tendency to align on microscale surfaces was higher and a similar degree of orientation was observed on patterned surfaces with 2- and 4- $\mu \mathrm{m}$ pitches. ${ }^{24}$ On the other hand, Lam et al. ${ }^{15}$ reported a decrease in myoblast orientation on patterned silicone surfaces when the groove width is increased from 3 and $6 \mu \mathrm{m}$ to $12 \mu \mathrm{m}$. Hence, in the present study, the groove width of $2 \mu \mathrm{m}$ was selected expecting it to be ideal for full scale orientation of the keratocytes (as was observed later on day 7).
Another observation is that some cells were out of focus indicating that they were at a higher elevation [Fig. 4(b)]. This can be explained by the fact that cells could adhere to the inclined surfaces of the groove and also by presence of a significant amount of ECM secreted as a response to the presence of the patterns, filling up the grooves and allowing cells to occupy positions higher than the patterns would normally allow. SEM micrographs supported this explanation. On day 7 SEM examination showed distinct cells settled on the groove side walls and a rougher surface than the original, smooth film surface [Fig. 5(a)]. On day 14 , cell layers could be seen within the grooves and the increase in the covered area and cell presence at the top of the ridges was apparent [Fig. 5(b)].

Main secretions of the keratocytes are collagen type I and proteoglycans; collagen type I is the main component of the corneal ECM and keratan sulfate is more abundant in the cornea structure than any other tissue. Thus, to study orientation of secreted ECM molecules, these two molecules were labeled by immunostaining on days 1 and 7 of incubation. For collagen type I staining the expectation was to have a significant background because the scaffolds themselves 

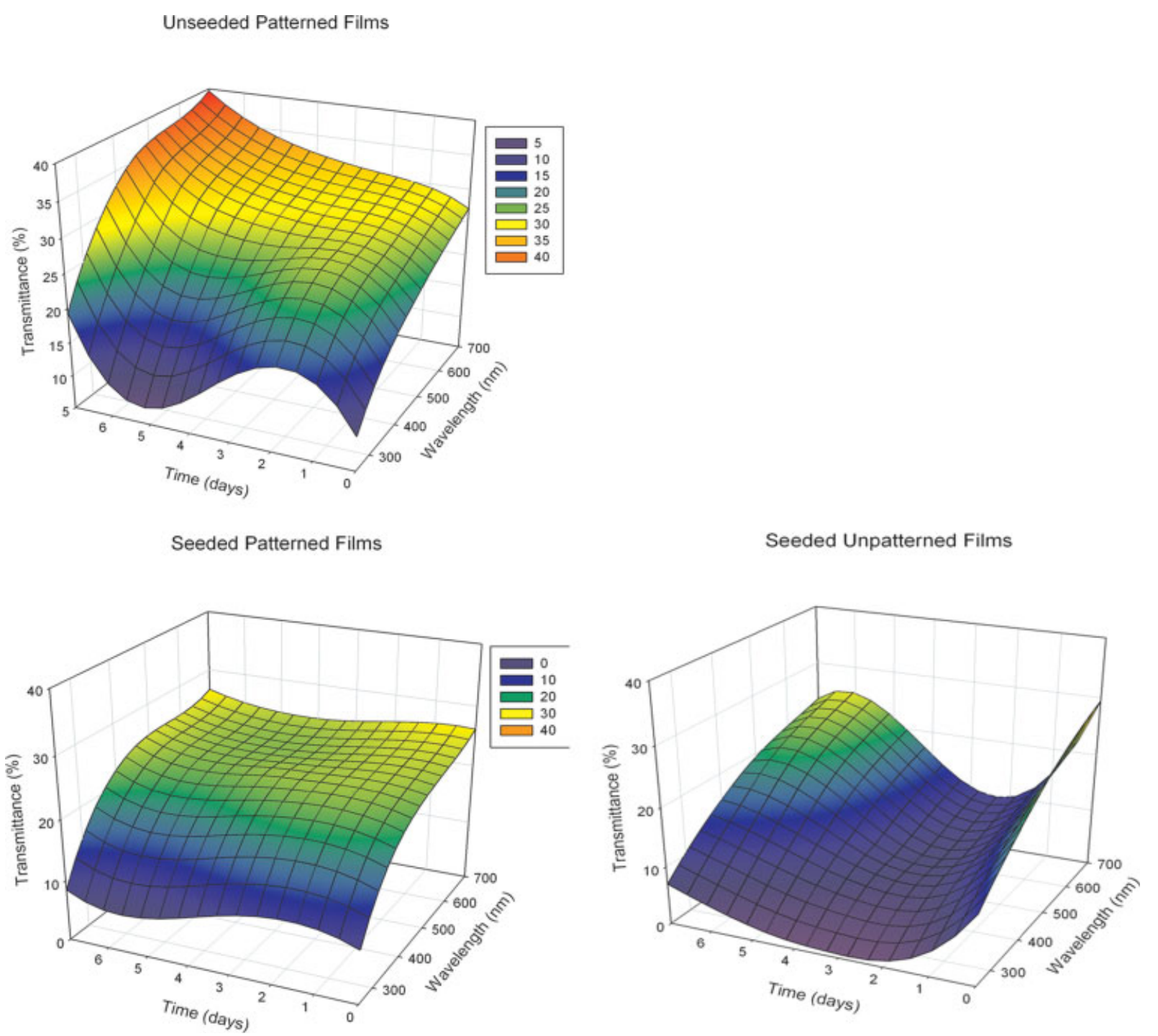

Figure 8. Transparency of collagen films in UV-vis range for a 7-day period. Percent transmission of (A) unseeded patterned films, (B) keratocyte seeded patterned films, and (C) keratocyte seeded unpatterned films (top, bottom left and bottom right, respectively). [Color figure can be viewed in the online issue, which is available at www.interscience.wiley.com.]

were also constructed of collagen type I so they could react with the antibody used. However, the background stain observed in the study was insignificant most probably due to the modification of the epitope recognized by the antibody during crosslinking. Collagen type I was more intracellular on day 1 [Fig. 6(b)]. On day 7, however, the localization of collagen type I was mainly extracellular [Fig. 6(c)]; the locations of the cells and the ECM did not completely overlap as on day 1 . Secretion was confined within the boundaries of the grooves; which further restricted the possible orientations of collagen molecules. Both collagen type I and keratan sulfate staining showed oriented secretion on patterned surfaces whereas no alignment was observed on unpatterned films (Figs. 6 and 7). Confinement of ECM secretion inside the grooves is quite promising because with the current in situ deg- radation rate during scaffold remodeling (with secreted collagen and proteoglycan) the oriented structure would still be present on the surface.

\section{Scaffold transparency}

Most distinctive feature of the cornea is its transparency. Transparency of cornea is strongly related to the structure of the ECM and also to the properties of the keratocytes. Under normal conditions corneal keratocytes are flat, lie between successive lamellae and maintain contact with each other. However, on patterned collagen films of this study they had a more spindle like shape mainly due to the topographical restriction imposed on them by the patterns. This is a 
compromise between the natural cellular morphology and the induction of oriented ECM secretion.

Transparency measurements showed that, there was a significant difference between the cell seeded films, unseeded patterned films, and cell seeded, unpatterned films $(p=0.001)$. On the patterned surfaces seeded with keratocytes, transparency was retained up to a certain level which was slightly lower than the original transparency of the unseeded films. This is a dynamic medium involving degradation of the original scaffold, cell number increase and ECM secretion. Decrease in transparency caused by cell growth was compensated by the oriented secretion and material loss due to degradation. Contribution due solely to degradation can be seen in Figure 8 (a). At $700 \mathrm{~nm}$, transparency of the patterned films rose from $28.6 \% \pm 0.4 \%$ to $38.1 \% \pm 0.3 \%$.

The difference between transparency of unseeded, patterned films $(28.6 \% \pm 0.4 \%)$ and unpatterned films $(31.4 \% \pm 0.9 \%)$ was slight and this observation is in agreement with the results of Mills et al. who used poly(lactic acid) films. ${ }^{25}$ On unpatterned films cell presence caused a severe decrease in transparency, followed by a gradual increase in the following days, but in spite of this improvement unpatterned films did not perform as well as the patterned ones. Transparency of unpatterned films on day 1 was $12.9 \% \pm$ $1.3 \%$ and on day 7 it increased to $21.7 \% \pm 1.1 \%$, which was less than that of the patterned films on day $7(26.0 \% \pm 0.8 \%)$ [Fig. $8(\mathrm{~b}, \mathrm{c})$ ]. The decrease observed initially could be related to the random distribution of the cells and subsequent disorganized secretion and the improvement was most probably the result of remodeling of the scaffold and the secreted molecules by the cells. Also, secretion of proteoglycans by the keratocytes might be effective on this positive trend since Orwin et al. observed an increase in transparency of collagen foams after incorporation of chondroitin sulfate. ${ }^{16}$

Corneal lamellae are much thinner (200 lamella in $500-\mu \mathrm{m}$-thick stroma) than the films used in this study $(42 \mu \mathrm{m})$. This film was chosen to localize keratocytes into the grooves and the depth of the groove prevents an attempt to decrease the thickness. Since light transmission is expected to increase with a decrease in the path within the material transparency of the artificial stromas prepared in this study should be significantly higher when appropriate thicknesses are used. For the samples subjected to degradation, there was a linear correlation between Degradation (as judged by weight loss) and Transparency ( $r=-0.9379)$. On the other hand, no linear correlation was found between Cell Proliferation and Transparency for keratocyte seeded patterned films $(r=-0.5531)$. This shows that the orientation of the cells and that of the secreted ECM also contribute to the development of transpar- ency, and not proliferation alone. Superior behavior of the patterned films showed that long range ordering of the cells was an important parameter in the development of transparent corneal implants. ${ }^{26}$

\section{CONCLUSION}

Keratocytes are quiescent cells of corneal stroma which are activated upon damage. Keratocytes can heal small wounds, but severe damages may result in scar formation due to the disoriented ECM secretion. Hence, methods that would promote aligned ECM secretion similar to that of natural corneal stroma would be very beneficial for cornea tissue engineering applications. In this study, human corneal keratocytes were grown on patterned collagen films and oriented secretion of collagen and keratan sulfate was observed. Degradation of the collagen films was slow enough to allow its replacement by the newly secreted ECM, and thus the patterned films were effective in acting as a topographical cue without interfering with the remodeling process. Transparency of these films was about $30 \%$ in the first 2 weeks of cell seeding and there was only a little decrease in the presence of the cells, indicating that organized ECM secretion and aligned cells did not lead to significantly increased light scattering. Conversion of these findings into 3D matrices may result in more efficient tissue engineering scaffolds which may lead to rapid cornea healing.

This project was funded by EU FP6 project "Cornea Engineering." Engin Vrana was partially supported by TUBITAK-BAYG 2210 scholarship.

\section{References}

1. Liung Z, Huang A, Pflugfelder SA. Evaluation of corneal thickness and topography in normal eyes using Orbscan corneal topography system. Br J Opthalmol 1999;83:774778 .

2. Adamis AP, Filatov V, Tripathi BJ, Tripathi RC. Fuchs' endothelial dystrophy of the cornea. Surv Ophthalmol 1993;38: 149-168.

3. Kim WJ, Rabinowitz YS, Meisler DM, Wilson SE. Keratocyte apoptosis associated with keratoconus. Exp Eye Res 1999; 5:475-481.

4. Wilson SE, Kim WJ. Keratocyte apoptosis: Implications on corneal wound healing, tissue organization and disease. Invest Ophthalmol Vis Sci 1998;2:220-226.

5. Meek KM, Leonard DW. Ultrastructure of the corneal stroma: A comparative study. Biophys J 1993;64:273-280.

6. West-Mays JA, Dwivedi DJ. The keratocyte: Corneal stromal cell with variable repair phenotypes. Int J Biochem Cell Biol 2006;38:1625-1631.

7. Maurice DM. Structure and transparency of the cornea. J Physiol 1956;136:263-286.

8. Chakravarti S, Petroll WM, Hassell JR, Jester JV, Lass JH, Paul J, Birk DE. Corneal opacity in Lumican-null mice: 
Defects in collagen fibril structure and packing in the posterior stroma. Invest Ophthalmol Vis Sci 2000;41:3365-3373.

9. Curtis ASG, Wilkinson C. Topographical control of cells. Biomaterials 1987;18:1573-1583.

10. Walboomers FX, Jansen JA. Cell and tissue behaviour on micro-grooved surfaces. Odontology 2001;89:2-11.

11. Kenar H, Köse GT, Hasirci V. Tissue engineering of bone on micropatterned biodegradable polyester films. Biomaterials 2006;27:885-895.

12. Recknor JB, Sakaguchi DS, Mallapragada SK. Directed growth and selective differentiation of neural progenitor cells on micropatterned polymer substrates. Biomaterials 2006;27: 4098-4108.

13. Csucs G, Michel R, Lussi JW, Textor M, Danuser G. Microcontact printing of novel co-polymers in combination with proteins for cell-biological applications. Biomaterials 2003;24: 1713-1720.

14. Bellamkonda RV. Peripheral nerve regeneration: An opinion on channels, scaffolds and anisotropy. Biomaterials 2006;27: 3515-3518.

15. Lam MT, Sim S, Zhu X, Takayama S. The effect of continuous wavy micropatterns on silicone substrates on the alignment of skeletal muscle myoblasts and myotubes. Biomaterials 2006;27:4340-4347.

16. Orwin EJ, Borene ML, Hubel A. Biomechanical and optical characteristics of a corneal stromal equivalent. J Biomech Eng 2003;125:439-445.

17. Hu X, Lui W, Cui L, Wang M, Cao Y. Tissue engineering of nearly transparent corneal stroma. Tissue Eng 2005;11:1710-1717.

18. Germain L, Auger FA, Grandbois E, Guignard R, Giasson M, Boisjoly H, Guerin SL. Reconstructed human cornea pro- duced in vitro by tissue engineering. Pathobiology 1999;67: $140-147$.

19. Li F, Griffith M, Li Z, Tanodekaew S, Sheardown H, Hakim M, Carlsson DJ. Recruitment of multiple cell lines by collagen-synthetic copolymer matrices in corneal regeneration. Biomaterials 2005;26:3093-3104.

20. Ber S, Köse GT, Hasirci V. Bone tissue engineering on patterned collagen films: An in vitro study. Biomaterials 2005;26: 1977-1986.

21. Vernon RB, Gooden MD, Lara SL, Wight TN. Microgrooved fibrillar collagen membranes as scaffolds for cell support and alignment. Biomaterials 2005;26:3131-3140.

22. Builles N, Bechetoille N, Justin V, Ducerf A, Auxenfans C, Burillon C, Sergent M, Damour O. Development of an optimised culture medium for keratocytes in monolayer. Biomed Mater Eng 2006;16(Suppl 4):95-104.

23. Wan Y, Wang Y, Liu Z, Qu X, Han B, Bei J, Wang S. Adhesion and proliferation of OCT-1 osteoblast-like cells on micro and nano scale topography structure poly(L-lactide). Biomaterials 2005;26:4453-4459.

24. Teixeira AI, Nealey PF, Murphy CJ. Responses of human keratocytes to micro- and nanostructured substrates. J Biomed Mater Res A 2004;71:369-376.

25. Mills CA, Navarro M, Engel E, Martinez E, Ginebra MP, Planell J, Errachid A, Samitier J. Transparent micro- and nanopatterned poly(lactic acid) for biomedical applications. J Biomed Mater Res A 2006;76:781-787.

26. Jester JV, Moller-Pedersen T, Huang J, Sax CM, Kay WT. The cellular basis of corneal transparency: Evidence for "corneal crystallins." J Cell Sci 1999;112:613-622. 